\title{
III) Discretionary Time: A Rejoinder
}

\author{
Robert E. Goodin • James Mahmud Rice • Antti Parpo • \\ Lina Eriksson
}

Accepted: 22 July 2009/Published online: 24 July 2010

(C) Springer Science+Business Media B.V. 2010

We thank Bittman (2010), both for his kind words concerning our book (Goodin et al. 2008) and for his considerable help with the early stages of our project. We shall take as read his admirable summary of our book and focus here purely on the major concern he raises - which judging from our discussions might be shared in certain national statistical offices as well.

Let us begin by reiterating what all parties to the debate happily agree. Historically, among time-use researchers (and national statistical offices and academic researchers and international organizations following them), there has been an absolutely standard way of calculating and reporting how much 'free time' people have. That is just how much time people have left over, after deducting the amount of time people actually spend in paid labor, unpaid household labor and personal care. That sort of calculation underlies Hochschild's (1997) analysis in The Time Bind, Schor's (1991) of The Overworked American and the OECD (2009) analysis of leisure time.

By that standard, however, the 'free time' of lone mothers is almost indistinguishable from that of individuals in dual-income no-kid (DINK) households. The amount of time, on average, that people spend in those activities is virtually identical in both kinds of household. But to say that lone mothers are no worse off than DINKs would be an utter nonsense. It ignores the palpable fact that lone mothers must work most of those long hours they do, just to meet bare necessities, whereas DINKs do not. For policy purposes, it is absolutely essential to find some way of distinguishing the case of people who work long hours because they choose to and the case of people who work long hours because they need to.

R. E. Goodin $(\bowtie) \cdot$ J. M. Rice

Research School of Social Sciences, Australian National University, Canberra, ACT 2614, Australia e-mail: Bob.Goodin@anu.edu.au

A. Parpo

Social Welfare Office, 31401 Somero, Finland

L. Eriksson

Department of Philosophy, Flinders University, GPO Box 2100, Adelaide 5001, Australia 
That is a simple point, long overlooked. But once pointed out, everyone's head nods emphatically in support. Certainly the heads of the most senior time-use researchers from the US, UK and Australia did, at the IATUR meetings where this author-meets-critics symposium originated. So too did the heads of senior representatives of various national statistical organizations and social policy organizations where we have discussed our results. It represents an 'oops' moment for the profession of time-use research at large, which is in our experience is universally acknowledged as such as soon as it is pointed out. Bittman certainly concurs with us about the crying need to distinguish, somehow, between people who have little 'free time' out of choice and people who have little 'free time' out of necessity. That is the major point that we most fervently want to put on the policy agenda.

Following on from that is, of course, the further question of exactly how best to specify how much time is 'necessary' to spend in the key activities of life. There, Bittman is tempted to go in a different direction from us. We will defend our own approach against Bittman's below. But let us emphasize at the outset that it is much, much more important to substitute some-any-measure of 'necessary time' for the now-standard time-use measures of 'actual time' in determining how time-pressured people really are. Disagreements over how 'necessary time' is best specified must not excuse persisting, for policy purposes, in focusing on utterly indefensible measures of 'free time' calibrated in terms of the amount of time 'actually' spent in key activities.

There are basically two ways of specifying how much time is 'necessary' to spend in any given activity. Call our approach the 'relative approach', and Bittman's the 'absolute approach'.

Our 'relative approach' mimics, in time terms, the now-standard way of calculating poverty lines in terms of money. According to the (old) OECD convention, much favored among academic poverty researchers as well, someone is 'poor' if his/her income is less than half the median income of people in his/her country (adjusting for household sharing and household size). That is a 'relative' standard, in the sense that poverty is relativized to the median income of people in your country. In specifying 'necessary time' in our book, we likewise relativize that to the standard practice of people in your country. We define 'necessary time in paid labor' in terms of how long it would take the person to earn a poverty-level income, thus defined. We specify 'necessary time' in the other two dimensions similarly in terms that are relative to how much time people in a particular society spend in those activities: "necessary time in unpaid household labor is half the median amount of time people in the country actually spend doing that, adjusting for household structure; and 'necessary time in personal care' is four-fifths the median. Our relative approach to specifying 'necessary time' in unpaid household labor and personal care sets about as tough a standard of necessity in these two realms as is set in the realm of paid labor by the OECD poverty line. Averaging across all six countries studied in our book (the US, Australia, Germany, France, Sweden and Finland), almost exactly the same proportion of people (10\%) fall below our standards of necessity in the dimensions of unpaid household labor and personal care as are living below the relative money poverty line (and hence fall below our standard of necessity in the dimension of paid labor).

The older approach to poverty which Bittman favors (and to which he has made a major contribution [Saunders et al. 1998]) defines poverty in more absolute terms. In poverty studies this is called a 'basket of goods' approach. Think of a shopping trolley. What do you need to put into the weekly shopping trolley to keep your family ticking over at a bare minimum level, and what would it cost to buy those goods? On the 'basket of goods' approach, that would represent the poverty line in money. And you can think, by extension, 
of what would be necessary for you to do in terms of unpaid household labor and personal care, and how long would it take you to do that? How much time is physiologically necessary (as opposed, per our approach, to socially conventional) to spend sleeping? How much time do you strictly need to spend bathing yourself and attending to your personal appearance? How many times a day do you strictly need to change the toddler's diaper, and how long do you strictly need to spend doing it? And so on.

We have two reasons for preferring the 'relative' to the 'absolute' (basket of goods) account. One is pragmatic, the other principled. The pragmatic point is simply this: it's hard to get agreement on what goes into a 'basket of goods' as being 'absolutely necessary', in time terms as much as in money terms. (It is also hard to get agreement or comparability when baskets of 'what is necessary' changes). Defining in this absolute way is what exactly needs to be done and how much time is strictly 'necessary' to do it is inevitably going to be highly contentious. We know as much from disputes over 'baskets of goods' for defining poverty. 'Is a TV really necessary in your basket, or not? After all', skeptics invariably point out, 'people lived perfectly well for many generations without them....'

The second, more principled reason we prefer the relative approach is connected to that. The relative approach builds on a good answer to the last question. Why do you need a TV, just because everyone else in your society has a TV? Simple: to participate in the life of your community, you need to be able to talk with others about what you've all seen on the TV. If most people have TVs, then you need one for precisely that reason (Townsend 1979).

More generally, time like money is a merely instrumental good, the usefulness of which to you is largely a function of how much you have relative to others with whom you are interacting. How much money you need to buy a bowl of rice depends on how much money is in the pocket of other people around you who also want to buy the same bowl of rice: that is the lesson of Sen (1981) analysis of the Great Bengal Famine. Likewise, how much time you need to spend keeping your house up to a socially acceptable level of cleanliness depends on how much time others around you have available to spend cleaning theirs. And whether you need to take the time to bake your children and their friends' cakes when they come home from school depends on whether their friends' parents have the time to bake them and their friends cakes. Similarly, how much time you need to spend bathing yourself and attending to your personal appearance depends on how much time others around you spend doing these activities. What you need to do, and how much time you need to spend doing it, is in a great many ways relative to what others in your society are doing and how much time they spend doing it. That is the important insight that is captured by our 'relative' approach to specifying 'necessary time'.

For reasons of both practicality and principle we therefore prefer our 'relative' to Bittman's 'absolute' way of specifying 'necessary time'. But above all, we and Bittman would reiterate with a single voice that it is crucial for policy-makers to get out of the habit of thinking about people's temporal welfare in terms of 'free time', taking no account of whether they lacked that out of choice or out of necessity.

\section{References}

Bittman, M. (2010). Goodin et al.'s new measure of freedom: A critique. Social Indicators Research (this issue).

Goodin, R., Rice, J., Parpo, A., \& Eriksson, L. (2008). Discretionary time: A new measure of freedom. Cambridge: Cambridge University Press, the International Social Science Council awarded this book the 2009 Stein Rokkan Prize for Comparative Social Science Research. 
Hochschild, A. R. (1997). The time bind. New York: Metropolitan Books.

OECD (2009) Measuring leisure in OECD countries, chap. 2. In Society at a Glance 2009: OECD social indicators. Paris: OECD. <http://www.oecd.org/els/social/indicators/SAG>.

Saunders, P., et al. (1998) Development of indicative budget standards for Australia. Policy Research Paper Number 74, Social Policy Research Centre, University of New South Wales. Canberra: Department of Social Security, Commonwealth of Australia.

Schor, J. (1991). The overworked American: The unexpected decline of leisure. New York: Basic Books. Sen, A. (1981). Poverty and famines. Oxford: Clarendon Press. See further Fred Hirsch, Social limits to growth (Cambridge, Mass.: Harvard University Press, 1976).

Townsend, P. (1979). Poverty in the United Kingdom. Harmondsworth, Mddx.: Penguin 